\title{
Technology of reusable assembly power pipe trench and temporary road system
}

\author{
Wang Chenglin ${ }^{1}$, Tian $\mathrm{Wei}^{1 *}$, Dong Wanduo ${ }^{1}$ \\ ${ }^{1}$ China Construction Seventh Engineering Division Corp. Ltd., Zhengzhou, 450004, China
}

\begin{abstract}
Based on the current situation of the temporary pipelines with disorderly layout and low integration, the temporary roads with time consuming, material consuming and environmentally unfriendly in, construction site, a new type of reusable assembly power pipe trench and temporary road system technology is proposed in this paper. The research background and research ideas of the technology are described; the partition, structure and connection of the system are designed; the stress of the system is checked by finite element method, and the main stress structure is optimized. The system has the advantage of high degree of integration, convenient transportation and installation, and high reusability, and it is in line with the modern construction concept of carbon emission reduction, green construction and civilized construction.
\end{abstract}

\section{Introduction}

Temporary pipelines and roads play a very important role in construction projects. An incomplete system make the pipe network disordered, easy to damage, difficult to turnover, frequent faults. And there are even safety accidents caused by pipeline faults. This puts forward higher requirements for the layout of temporary hydropower projects on the construction site, and also promotes the development trend of modernization, technology and intensification[1] of hydropower network.

The hardening degree of the temporary road on the construction site is relatively high, and the construction period is relatively tight[2], so the temporary road will directly affect the construction progress of the project. At present, the main form of temporary roads in China's construction projects is cast-in-place reinforced concrete temporary roads [3]. The prefabricated structure has the characteristics of good product quality, high production efficiency, fast construction speed and highly integrated functions [4]. In North America, Europe, Japan and other developed regions, prefabricated structure has been widely used [5]. In this paper, combined with the idea of prefabricated structure, a reusable assembly power pipe trench and temporary road system is designed to solve the above problems.

\section{Design ideas}

The design ideas of reusable assembly power pipe trench and temporary road system draws lessons from the ideas of comprehensive pipe gallery, and consider integrating the drainage, water supply, strong and weak current systems into comprehensive power pipe trench to realize unified management.

\section{Material selection}

In the construction site, the system needs to meet the requirements of short processing cycle, fast assembly speed, low foundation requirements, good mechanical properties and low comprehensive cost.

\subsection{Temporary road system}

SP prestressed hollow plate (hereinafter referred to as SP plate) is a kind of large-span prestressed concrete hollow plate[6]. Due to the low requirement of SP plate for foundation, in order to reduce the area of foundation treatment, support will be set up and SP plate will be put on the support. The support adopts the conventional reinforced concrete beam form, and the beam section is selected from the rectangular section, trapezoidal section and triangle shape section (as shown in Figure 1).

\subsection{Power pipe trench system}

Power pipe trench system includes drainage zoning, water supply zoning, strong and weak current zoning. Combined with the design idea of the comprehensive ditch, the water supply zoning and the strong and weak current zoning are integrated into the small comprehensive ditch, and the function of the drainage zoning is incorporated into the prefabricated drain.

\footnotetext{
*Corresponding author: 276570464@qq.com
} 


\section{Cross-sectional design}

After material selection and preliminary design of each functional zoning, through assembly, the cross-section combination form of reusable assembly power pipe trench and temporary road system can be obtained, as shown in Figure 2. The road zoning is composed of SP plate, support A and support B; the drainage zoning is composed of drain; the water supply zoning and strong and weak current zoning are integrated into comprehensive pipe trench.

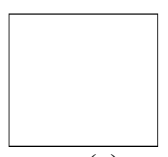

(a)

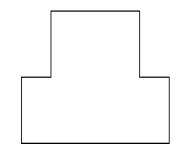

(b)

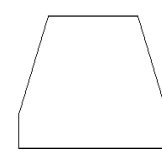

(c) (a) rectangular section (b) triangle shape section (c) trapezoidal section

Fig.1. Schematic diagram of support section

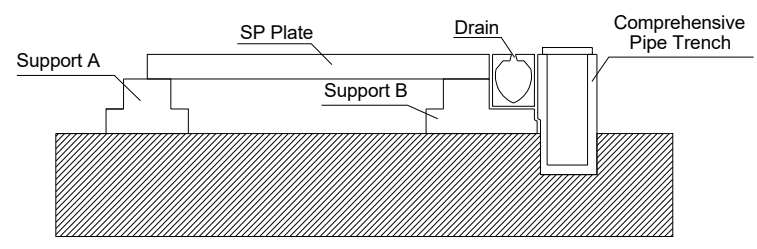

Fig.2. Sectional diagram of reusable assembly power pipe trench and temporary road system

\section{Longitudinal design}

\subsection{Determination of longitudinal modulus}

Basic module is the basic unit of dimension in module coordination. If the module is too large, the processing and handling of components is not convenient. If the module is too small, the installation is complex and uneconomic. Therefore, the modulus value should be comprehensively considered and designed in accordance with the Chinese national standard "Standard for modulus coordination of building" [7].

\subsection{Longitudinal connection}

For longitudinal connection, firstly, a connecting hole is set on the upper side of the end of the trench, and the bolt is penetrated into the connecting hole to connect two adjacent sections of the trench, as shown in Figure 3; then, mortar is poured between the fabricated sections. Mortar will change SP plate from one-way board to two-way board to a certain extent, which has a certain gain to the stress of the structural system; at the same time, it is also conducive to the improvement of the waterproof performance of the whole system. The pipe trench integrates the power supply system and water supply system, so we should pay more attention on the waterproof effect.

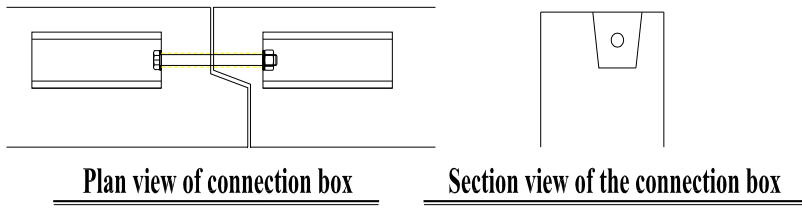

Fig.3. Schematic diagram of bolt connection

\section{Finite element analysis}

The finite element model of the system is established by ABAQUS software to analyse the overall stress of the system and optimize the main stress structure.

\subsection{The establishment of the model}

SP plate, the main materials are C45 concrete and prestressed steel strand. C45 concrete is simulated by three-dimensional solid homogeneous element with density of $0.6716 * 2500 \mathrm{~kg} / \mathrm{m}^{3}$, elastic modulus of 3.25 $* 10^{10} \mathrm{~Pa}$ and Poisson's ratio of 0.2 ; prestressed steel strand is simulated by one-dimensional truss element with density of $7900 \mathrm{~kg} / \mathrm{m}^{3}$, elastic model of $1.95 * 10^{11} \mathrm{~Pa}$ and Poisson's ratio of 0.31 . The support is made of $\mathrm{C} 45$ concrete. The three-dimensional solid homogeneous element is used to simulate the soil with the elastic modulus of $2.6 * 10^{8} \mathrm{~Pa}$, the Poisson's ratio of 0.42 , the density of $1900 \mathrm{~kg} / \mathrm{m}^{3}$, the cohesion of $19 \mathrm{kPa}$, the friction angle of $31^{\circ}$ and the expansion angle of $29^{\circ}$ [8].

In the simulation, vehicle load and prestress are mainly considered. The model refers to the layout of vehicle load in "General specifications for design of highway bridges and culverts" [9]. The front two wheels generate $30 \mathrm{kN}$ load, the four wheels in the middle generate $240 \mathrm{kN}$ load, the rear four wheels generate $280 \mathrm{kN}$ load, and the axle spacing between the two rows of wheels is $1.8 \mathrm{~m}$. In the model, cooling method is used to simulate pretensioned tendons in SP plate. The established finite element model is shown in Figure 4.

\subsection{Results of finite element simulation}

After the calculation, we found that the maximum deformation occurred in the center of the SP plate. When the width of the SP plate was $8 \mathrm{~m}$, the maximum deflection reached $73.08 \mathrm{~mm}$, which was $0.9135 \%$ of the total length of the SP plate. The deflection met the relevant requirements.

The maximum stress appeared in the prestressed reinforcement, and the maximum stress in the concrete structure appeared in the contact area between the SP plate and the support with the initial calculation result of 28.847 MPa. The stress value at this point was large, which indicated that it is necessary to further optimize the design of the support. The maximum stress in the soil was 155.56 $\mathrm{kPa}$, which could meet the stress requirements at the construction site. 


\section{Optimization for design}

From the previous analysis, it can be seen that the support has a large force and needs further optimization design. The support A and B are similar. The only difference is that the support A extends one foot to match the size of the drain to facilitate the installation of the drainage system. Therefore, taking support B as an example, the optimal design is carried out, and support B is shown in Figure 5.

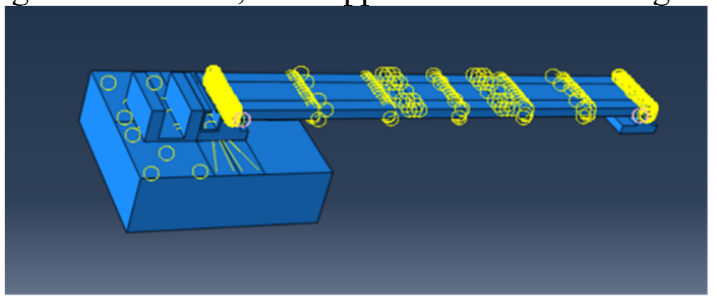

Fig.4.Schematic diagram of finite element model

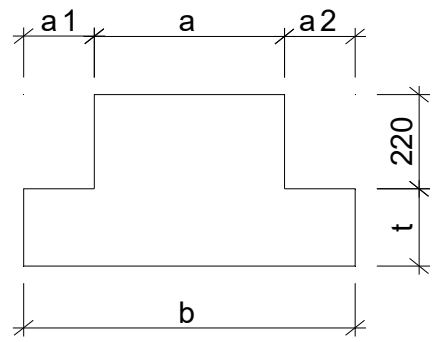

Fig.5. Sectional diagram of support B

The width of the upper edge is a; the width of the left side is a1; the width of the right side is a2; the width of the lower edge of the support is $\mathrm{b}(\mathrm{b}=\mathrm{a} 1+\mathrm{a}+\mathrm{a} 2)$; the thickness of the upper part is to match the height of the drain (the thickness of the upper part + the thickness of the SP plate $=$ the thickness of the drain), so it is temporarily set at $220 \mathrm{~mm}$; the thickness of the lower part is t. Through the finite element simulation, the maximum stress $S_{\max }$ on the support, the stress $S_{\text {mid }}$ at the center of the bearing mass center, the stress $S_{\text {bot }}$ at the center of the bottom of the support, and the maximum stress coefficient $\mathrm{Sv}_{\max }$, the stress coefficient $\mathrm{Sv}_{\text {mid }}$ at the center of the mass and the stress coefficient $\mathrm{Sv}_{\text {bot }}$ at the bottom center are recorded, and the cost of the component (volume) is considered in the stress coefficient.

\subsection{The influence of thickness $t$}

According to the simulation results (see Fig. 6), the thickness $\mathrm{t}$ of the lower part has little effect on the maximum stress value $S_{\max }$; in the range of $0-180 \mathrm{~mm}, \mathrm{t}$ has a significant effect on $\mathrm{S}_{\mathrm{mid}}$; in the range of $40-140 \mathrm{~mm}$, $\mathrm{t}$ has a significant effect on $\mathrm{S}_{\text {bot }}$. After considering the component cost, $\mathrm{Sv}_{\max }$ and thickness $\mathrm{t}$ are positively correlated; $\mathrm{Sv}_{\text {mid }}$ and thickness $\mathrm{t}$ have a certain cubic function relationship in the range of $t$ on $40-220 \mathrm{~mm}$, and have an extreme value around $180 \mathrm{~mm} ; \mathrm{Sv}_{\text {bot }}$ and thickness $t$ have an exponential function relationship in the range of $\mathrm{t}$ on $40-220 \mathrm{~mm}$, and the influence of thickness $t$ on $\mathrm{Sv}_{\mathrm{bot}}$ is not obvious when $t$ exceeds $160 \mathrm{~mm}$. Based on the above stress analysis, and considering the structural requirements and processing convenience, the value of $t$ can be $160-180 \mathrm{~mm}$.

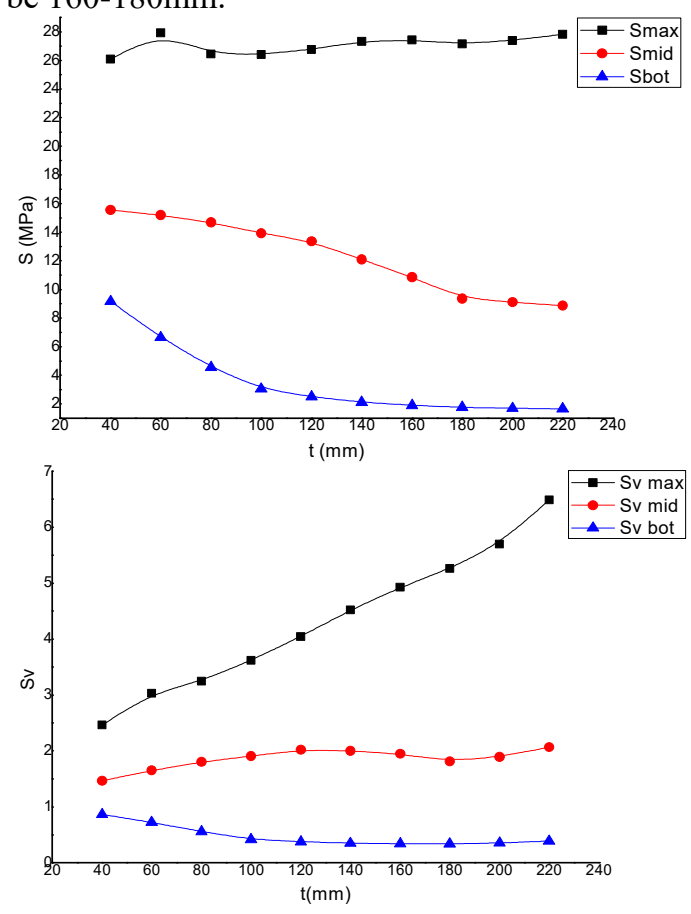

Fig.6.Relationship between thickness $t$ and stress $S$

(The left figure does not consider the component cost, while the right figure does)

\subsection{The influence of width a1}

It can be seen from Figure 7 that the width a1 has a certain influence on the stress value in the range of $305-390 \mathrm{~mm}$, but it is not obvious; after considering the cost factor, a1 has a small linear relationship with $\mathrm{Sv}_{\max }$, and a1 has no obvious influence on $\mathrm{Sv}_{\text {mid }}$ and $\mathrm{Sv}_{\text {bot. }}$. Considering material saving, the range of $305-315 \mathrm{~mm}$ is preferred for a 1 .
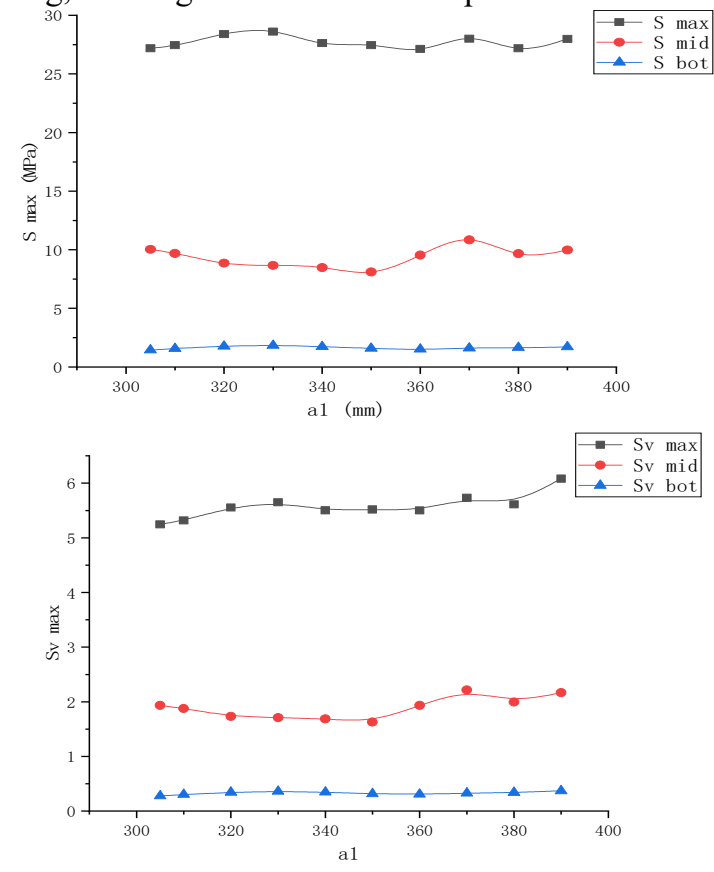

Fig.7.Relationship between width a1 and stress S 
(The left figure does not consider the component cost, while the right figure does)
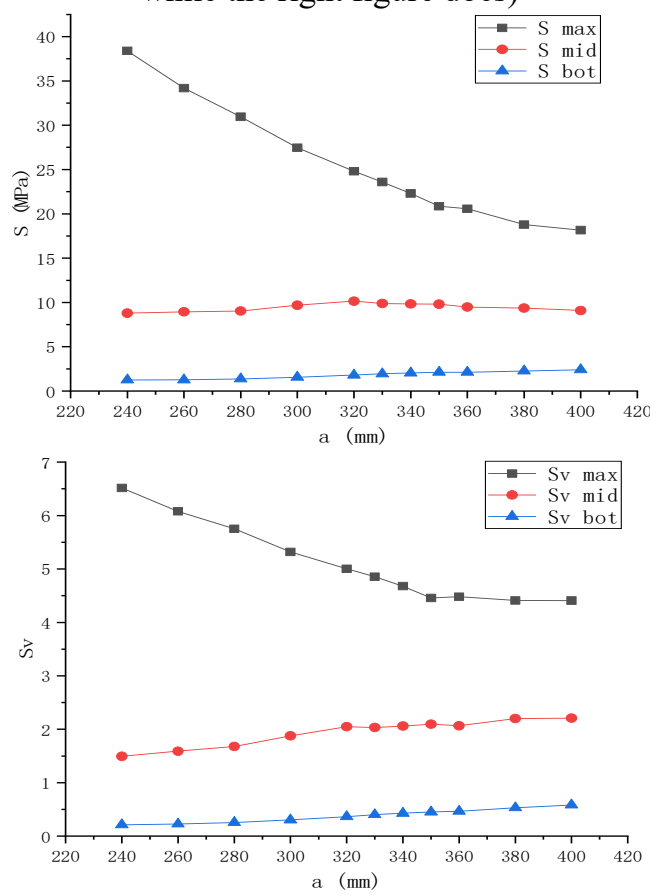

Fig.8.Relationship between width a and stress S

(The left figure does not consider the component cost, while the right figure does)
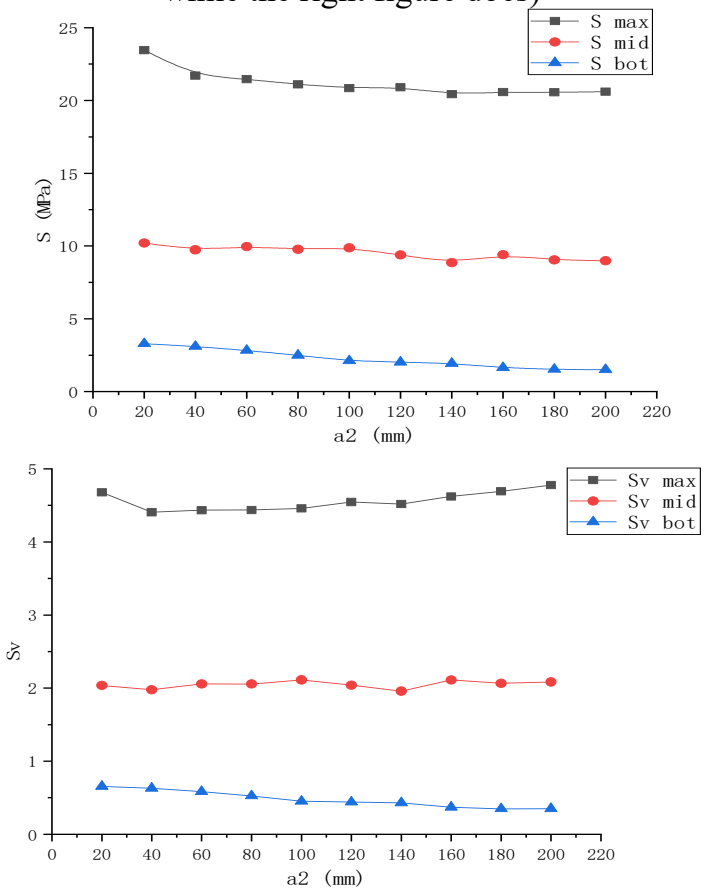

Fig.9.Relationship between width a2 and stress $\mathrm{S}$

(The left figure does not consider the component cost, while the right figure does)

\subsection{The influence of width a}

It can be seen from Figure 8 that Smax decreases with the increase of a in the range of $240-400 \mathrm{~mm}$, and the effect of a on $\mathrm{S}_{\text {mid }}$ is not obvious, showing a weak quadratic function relationship. The linear growth relationship between a and $\mathrm{S}_{\text {bot }}$ has a small slope. Considering the cost coefficient, $\mathrm{SV}_{\max }$ decreases linearly with a when a is 240 $350 \mathrm{~mm}$, and a has no obvious effect on $\mathrm{Sv}_{\max }$ when a is more than $350 \mathrm{~mm} ; \mathrm{Sv}_{\text {mid }}$ and $\mathrm{Sv}_{\text {bot }}$ increase linearly with a when a is $240-400 \mathrm{~mm}$. Considering the obvious effect of a on the maximum stress, the width a can be selected around $350 \mathrm{~mm}$.

\subsection{The influence of width a2}

As can be seen from Figure 9, the effect of parameter a2 on stress is not significant. By comparison, when a2 is about $70 \mathrm{~mm}$ and $130-140 \mathrm{~mm}$, there is a lower stress value. And when a2 is $130-140 \mathrm{~mm}$, the maximum stress value is smaller, so a 2 can be selected in this interval.

\section{Conclusion}

Through the finite element calculation and optimization design, the force of the reusable assembly power pipe trench and temporary road system can meet the stress requirements; the system has high integration, meets the requirements of green construction and civilized construction, has the characteristics of easy operability and turnover. After a single project is completed, it can be used in other projects again, to reduce the use cost. So this system has broad application prospects and value of further investigation.

\section{Acknowledgments}

Thanks for the financial support of scientific research projects cscec7b-2019-Z-11 of China Construction Seventh Engineering Division Corp. Ltd..

\section{Reference}

1. Gu, B.G. (2021) Design of Fabricated Concrete Structural Utility Tunnel Bridge. Urban Roads Bridges \& Flood Control, (262),65-68.

2. Li, H.L., Lu, Y.Z., Zhang, J.L., et a1. (2019) Construction Technology of Assembled Drainage System of Sponge City for Urban Road. Building Construction, 41(11): 2066-2068.

3. Zhang, W.D.(2011) The Design and Construction of the Temporary Road of Tanghe Hydropower Station Project. Journal of Library and Information Science, 21 (21): 197-198.

4. Jiang, Q.J.(2010) Summary On Development Of Assembled Concrete Building Both Home And Abroad. Architecture Technology, 41(12):1074-1077.

5. Li, X.M.(2011) The Development and Application of Key Technologies of Assembly Concrete Structure in Foreign Countries. Housing Industry, 6(131):16-18.

6. Xu, X.K., Tian, W., et a1.(2019) Design and application of composite prestressed hollow floor plates in high-rise assembly concrete structure. Building Structure, 49(49):869-874. 
7. National Standards of The People's Republic of China Standard for Modulus Coordination of Building (GB/T 50002-2013). Beijing: China.

8. Zhu, X.R., Wang, J.C.(2005) Introduction to Partly Soil Models in ABAQUS Software and Their Application to The Geotechnical Engineering. Rock and Soil Mechanics, 25(2): 144-148.

9. Profession Standard of The People's Republic of China, General Specifications for Design of Highway Bridges and Culverts (JTG D60-2015). Beijing: China. 